\title{
Synthesis of Azolines and Imidazoles and their Use in Drug Design
}

\author{
Alicia Reyes-Arellano*, Omar Gómez-García and Jenifer Torres-Jaramillo
}

National Polytechnic Institute, National School of Biological Sciences, Department of Organic Chemistry, Mexico City, Mexico

\begin{abstract}
Heterocycles are very important functional groups, especially in medicinal chemistry. They are not only pivotal in the synthesis of drugs, but also form part of the structure of a diversity of drugs, vitamins, natural products and biomolecules. The importance of azolines and imidazoles in heterocycles lies in the fact that their derivatives are known for analgesic, antifungal, antihypertensive, antiobesity, anticancer, and other biological activity. Additionally, they can inhibit butyrylcholinesterase, acetylcholinesterase, carboxylesterase and quorum sensing. Due to these properties, the present contribution reviews the use of azoline and imidazole moieties in recent drug synthesis based on classic as well as non-classic methods, the latter employing microwave and sonication energies. Also included is the preparation from oxazoline of nanostructured material having biomedical applications. Hence, the present focus is on the synthesis of azolines and imidazoles that are directly involved in the preparation of drug precursors and potential drugs.
\end{abstract}

Keywords: Azolines and imidazoles synthesis; Azolines and imidazoles in drug design; Nanoparticles from oxazolines

\section{Introduction}

Heterocycles are a very important functional group, especially in medicinal chemistry, because they constitute a common structural moiety in many drugs [1-4]. Azolines and imidazoles are key groups inside heterocycles, as they are not only a cornerstone of the synthesis pathway of these compounds, but also form part of potential [5] and marketed drugs [2]. Furthermore, in some cases azolines and imidazoles are the pharmacophore in drugs [6,7]. Consequently, azoline and imidazole synthesis has great importance in drug research.

The various interesting reviews of azolines and imidazoles [8-10] either focus on synthetic methods for obtaining these compounds or their biological activity, or both of these topics but with greater emphasis given to one of them [10]. In the current review, we focus on the synthesis of azolines and imidazoles that are directly involved in the preparation of drug precursors and the synthesis of potential drugs. We first discuss azolines and then imidazoles.

\section{Azolines}

Azolines are five-membered heterocycles with one double bond in the ring and two heteroatoms at positions 1 and 3, one of which is always nitrogen. Whereas imidazolines also contain nitrogen, oxazolines include oxygen, and thiazolines sulfur. Figure 1 shows some imidazolines, oxazolines and thiazolines that are either potential drugs or have important biological activity.

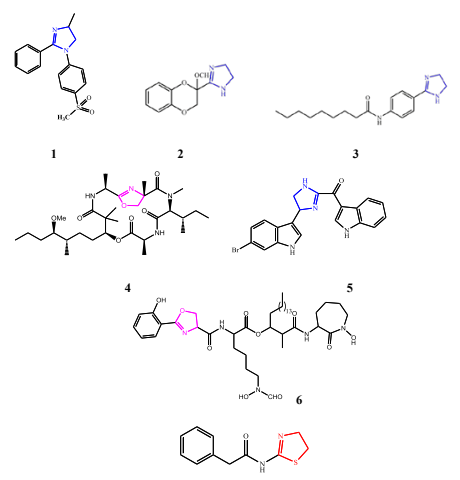

Figure 1: Examples of biologically active azolines, including blue imidazolines, pink oxazolines, and red thiazolines.
Compound $\mathbf{1}$ acts as a COX-2 inhibitor precursor [11], compound 2 methoxy-idazoxan / RX821002 ( $\alpha 2$ ), as an $\alpha$-adrenergic antagonist [1], compounds 3 and 7 as quorum sensing inhibitors [12,13], compound 4 , epi-oxazoline halipeptine $\mathrm{D}$, as a potent anti-inflammatory agent [14], compound 5, (-)-spongotine $\mathrm{A}$, as an antitumor agent with moderate cytotoxicity against human leukemia K-562 [15,16], and compound 6, brasilibactin A, as a cytotoxic siderophore [17].

\section{Synthesis and pharmacological activity of azolines}

The synthetic routes for building azolines can be divided into classic methods that use conventional energy, and non-classic methods accomplished with microwave (MW) or ultrasound energy.

Classical methods of synthesis: One commonly used method for the synthesis of azolines starts from an aldehyde and a source of heteroatoms, usually an ethylenediamine for imidazolines, an ethanolamine for oxazolines, and a cysteamine for thiazolines. After obtaining azolidines in this way, oxidants (e.g., I2, tertbuthyl hypochlorite $(t-\mathrm{BuOCl}), \mathrm{N}$-chlorosuccinimide (NCS), $\mathrm{N}$ bromosuccinimide (NBS) and $N$-iodosuccinimide (NIS) are utilized to achieve azolines. For instance, NCS and t-BuOCl have been applied to the total synthesis of (-)-spongotine A, 5 [15]. In other reactions, oxidation with NCS gave an $88 \%$ yield, but spongotine was obtained at $52 \%$ yield (Scheme 1 ).

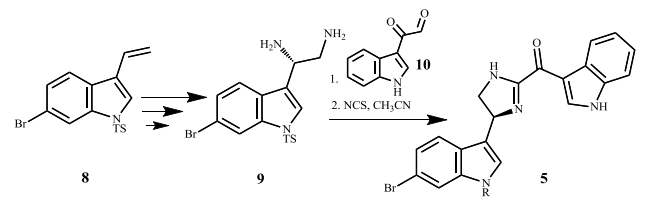

Scheme 1: Total synthesis of (-)-spongotine A, which displays moderate cytotoxicity against human leukemia K-562.

*Corresponding author: Alicia Reyes-Arellano, National Polytechnic Institute National School of Biological Sciences, Department of Organic Chemistry, Campus Santo Tomas, Carpio and Plan de Ayala S/N Colonia Santo Tomas, 11340 Mexico City, Mexico, Tel: +57296300; E-mail: areyesarellano@yahoo.com.mx

Received September 03, 2016; Accepted September 15, 2016; Published September 20, 2016

Citation: Reyes-Arellano A, Gómez-García O, Torres-Jaramillo J (2016) Synthesis of Azolines and Imidazoles and their Use in Drug Design. Med Chem (Los Angeles) 6: 561-570. doi:10.4172/2161-0444.1000400

Copyright: (c) 2016 Reyes-Arellano A, et al. This is an open-access article distributed under the terms of the Creative Commons Attribution License, which permits unrestricted use, distribution, and reproduction in any medium, provided the original author and source are credited. 
NBS-mediated reactions have in some cases required some of the longest reaction times. Nevertheless, NBS was used to synthesize 30 imidazoline inhibitors of cyclooxygenase-2 (COX-2), with a consequent anti-inflammatory activity [11]. Scheme 2 shows an example of the synthesis of a COX-2 inhibitor precursor 13, which is then oxidized to a COX-2 inhibitor, imidazole [11].

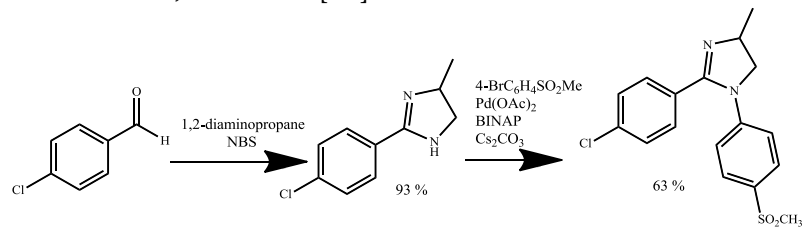

11

12

Scheme 2: Synthesis of a COX-2 inhibitor precursor

Amino alcohols and 4-ethoxy-4-iminobutanenitrile have also been employed to obtain new enantiomerically pure 2-cyanoethyloxazolines 18 in one step with good to excellent yields (73-96\%). This was accomplished by following a procedure appropriate for the selective synthesis of mono-oxazolines, which display antioxidant, antimicrobial and analgesic activities [18] (Scheme 3).

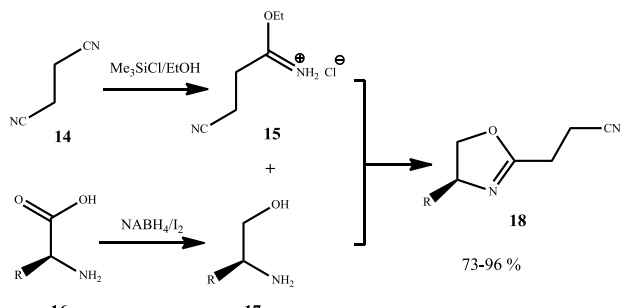

Scheme 3: Synthesis of 2-cyanoethyl-oxazolines, with antioxidant, antimicrobial and analgesic activities.

Padmavathi et al. [19] reported a new class of sulfone-linked pyrrolyl oxazolines and thiazolines 20 and 21, the synthesis of which was carried out with a one-pot methodology using transarylsulfonylethenesulfonyl-acetic acid methyl ester and ethanolamine or cysteamine, respectively. In the presence of a lanthanide chloride, $\mathrm{SmCl}_{3}$, aromatic compounds $\mathbf{2 2}$ and $\mathbf{2 3}$ were also obtained (Scheme 4). Compounds containing pyrrole and thiazoline possess excellent antimicrobial activity, while those including pyrrole and oxazoline show good antioxidant properties.

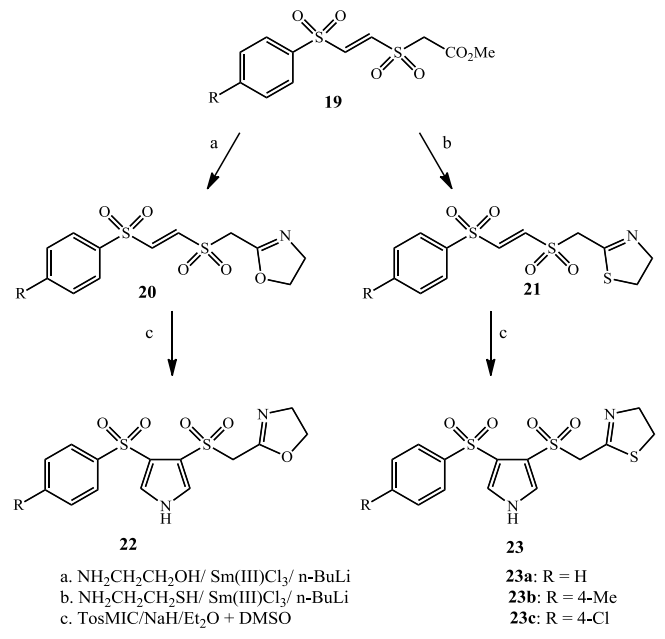

Scheme 4: Synthesis of pyrrolyl oxazolines and pyrrolyl thiazolines, with antioxidant and antimicrobial properties, respectively.
Altintop et al. [20] synthesized 40 compounds 29 by reacting a-thiophenoxy esters 25 with hydrazine and then followed by phenyl isothiocyanate. Afther wards, a-bromo acetophenone 28 derivatives were added to achieve 40 thiazolines having with one exo double bond (Scheme 5). The compounds were evaluated for as antibacterial, or antifungal activity agents, orand in the case of one compound, was tested as for anticancer activity against C6 glioma cells. All compounds exhibited significant antifungal activity against $T$. harzianum, $A$. ochraceus, F. solani, F. moniliforme, and/or F. culmorum. It was observed that the compound bearing 1-phenyl-1H-tetrazole and $p$-chlorophenyl moieties displays an inhibitory effect against $P$. aeruginosa, while it was also found that the compound, having 1-phenyl-1H-tetrazole and non-substituted phenyl moieties $\left(\mathrm{IC}_{50}=8.3+/-2.6 \mathrm{mg} / \mathrm{mL}\right.$ ), was more effective than cisplatin $\left(\mathrm{IC}_{50}=13.7+/-1.2 \mathrm{mg} / \mathrm{mL}\right.$ ).

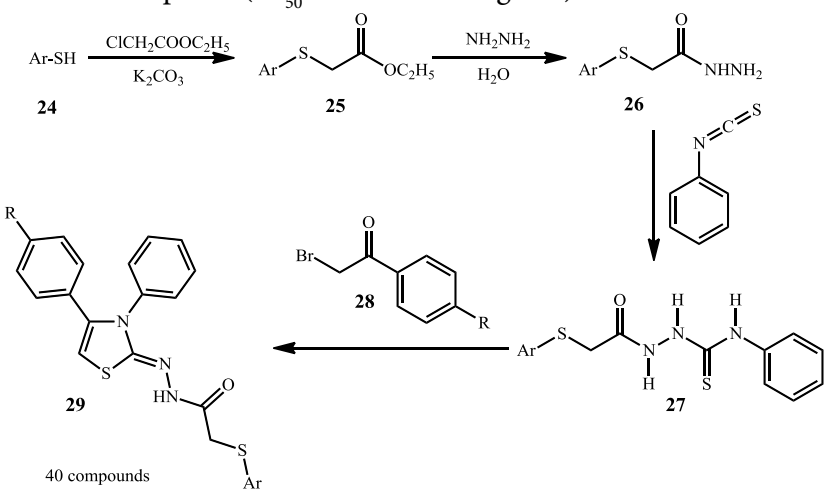

Scheme 5: Synthesis of thiazolines with antibacterial, antifungal and/or anticancer activity.

Thiazoline hydrohalide was also synthesized from $N$-allylthiourea, which is obtained from allylisothiocyanate $\mathbf{3 0}$ and the corresponding amine 31, as can be appreciated in Scheme 6. It is known that thiazines are formed in this type of reaction under conditions of polar solvents and high temperature. Conversely, thiazolines hydrohalide $\mathbf{3 4}$ were obtained in good yields (Scheme 6) [21]. They were evaluated as acetylcholinesterase (AChE), butyrylcholinesterase (BChE), and carboxylesterase $(\mathrm{CaE})$ inhibitors. Of the 30 compounds evaluated, only 5 were selective inhibitors of $\mathrm{BChE}$, both $\mathrm{BChE}$ and $\mathrm{ChE}$, or $\mathrm{CaE}$ [21].

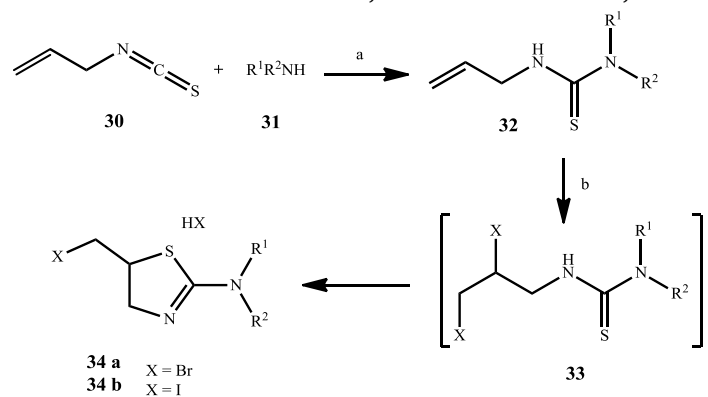

Scheme 6: Starting from allylisothiocyanate, synthesis of thiazolines that are inhibitors of $\mathrm{BChE}, \mathrm{ChE}$, or $\mathrm{CaE}$.

\section{Non-classic methods of synthesis:}

- Microwave energy: When synthesizing 2-aryloxy methyl oxazolines $\mathbf{3 7}$ with carboxylic acid derivatives $\mathbf{3 6}$ and ethanol amine via MW energy operating at $20 \%$ for $5-10 \mathrm{~min}$, good yields were obtained [22] (Scheme 7). Since the time is very short and the MW power low, this can be considered a very good method (even though the authors did not mention the total MW power). Compounds 37a-n were screened for anti-inflammatory and ulcerogenic activities, 
finding that compounds $\mathbf{3 7 b}(48.2 \%), 37 \mathbf{h}(48.5 \%)$ and $37 \mathrm{l}(46.5 \%)$ display significant anti- inflammatory activity. On the other hand, these compounds had lower ulcerogenic activity than the standard drugs, aspirin and phenylbutazone [22].

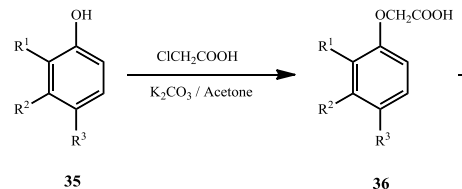

$37 \mathrm{a}: \mathrm{R} 1=\mathrm{R} 2=\mathrm{H}, \mathrm{R} 3=\mathrm{CH} 3$

$37 \mathrm{c}: \mathrm{R} 1=\mathrm{Br}, \mathrm{R} 2=\mathrm{R} 3=\mathrm{H}$

37e: $\mathrm{R} 1=\mathrm{Cl}, \mathrm{R} 2=\mathrm{R} 3=\mathrm{H}$

37g: $\mathrm{R} 1=\mathrm{R} 3=\mathrm{H}, \mathrm{R} 2=\mathrm{CH} 3$

37i: R1 $=\mathrm{R} 2=\mathrm{H}, \mathrm{R} 3=\mathrm{F}$

$37 \mathrm{k}: \mathrm{R} 1=\mathrm{R} 2=\mathrm{H}, \mathrm{R} 3=\mathrm{NO} 2$

$37 \mathrm{~m}: \mathrm{R} 1=\mathrm{F}, \mathrm{R} 2=\mathrm{R} 3=\mathrm{H}$

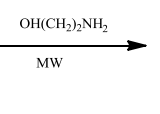

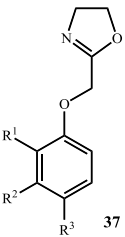

37b: $\mathrm{R} 1=\mathrm{R} 2=\mathrm{H}, \mathrm{R} 3=\mathrm{Cl}$ 37d: $\mathrm{R} 1=\mathrm{CH} 3, \mathrm{R} 2=\mathrm{R} 3=\mathrm{H}$ 37f: $\mathrm{R} 1=\mathrm{H}, \mathrm{R} 2=\mathrm{CH} 3, \mathrm{R} 3=\mathrm{Cl}$ $37 \mathrm{~h}: \mathrm{R} 1=\mathrm{R} 2=\mathrm{H}, \mathrm{R} 3=\mathrm{Br}$ 37j: R1 $=\mathrm{NO} 2, \mathrm{R} 2=\mathrm{R} 3=\mathrm{H}$

371: $\mathrm{R} 1=\mathrm{R} 2=\mathrm{CH} 3, \mathrm{R} 3=\mathrm{H}$

$37 \mathrm{n}: \mathrm{R} 1=\mathrm{R} 3=\mathrm{H}, \mathrm{R} 2=\mathrm{Cl}$

Scheme 7: Synthesis of oxazolines with anti-inflammatory activity by using MW energy.

- Ultrasound energy: Ultrasound energy has proven to minimize waste, decrease reaction times, and sometimes eliminate the use of solvents in organic chemistry synthesis. Since these are good properties for green chemistry [23], its use will undoubtedly increase. Ultrasound was utilized in one study on imidazoline synthesis by reacting aromatic aldehydes and ethylenediamine, with NBS as oxidant and water as solvent, to achieve good to excellent yields in 12-18 min. [24] (Scheme 8). The resulting imidazolines 40 were evaluated as monoamine oxidase (MAO) inhibitors, finding that they have activity in the micro molar $(\mu \mathrm{M})$ range with good selectivity [24]. When applying ultrasound energy to mediate azoline synthesis, we verified the high efficiency of this methodology, attaining imidazoline $\mathbf{4 0 j}$ in $12 \mathrm{~min}$ (81\% yield) and alkylphenoxy imidazolines in 20 min with moderate to good yields. Our interest in azolines lies in antiquorum sensing activity [12,13].

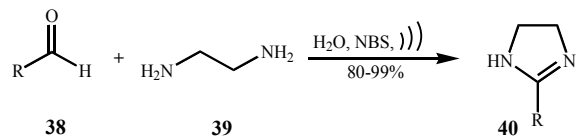

\begin{tabular}{|c|c|c|c|}
\hline Entry & $\mathbf{R}$ & $\begin{array}{l}\text { Time } \\
(\min )\end{array}$ & Yield (\%) \\
\hline $40 \mathrm{a}$ & $\mathrm{Ph}$ & 12 & 99 \\
\hline $40 \mathrm{~b}$ & Me-4-Ph & 18 & 95 \\
\hline $40 \mathrm{c}$ & MeO-4-Ph & 15 & 92 \\
\hline 40d & (MeO)2-3,4-Ph & 15 & 90 \\
\hline $40 \mathrm{e}$ & $(\mathrm{MeO}) 3-3,4,5-\mathrm{Ph}$ & 15 & 86 \\
\hline $40 \mathrm{f}$ & Ph-4-O-C(O)-Ph & 15 & 84 \\
\hline $40 \mathrm{~g}$ & Cl-4-Ph & 18 & 98 \\
\hline $40 \mathrm{~h}$ & Cl-2-Ph & 15 & 92 \\
\hline $40 \mathrm{i}$ & $\mathrm{Cl}_{2}-2,4-\mathrm{Ph}$ & 12 & 93 \\
\hline $40 \mathrm{j}$ & $\mathrm{NO}_{2}-4-\mathrm{Ph}$ & 18 & 82 \\
\hline $40 \mathrm{k}$ & $\mathrm{NO}_{2}-3-\mathrm{Ph}$ & 15 & 96 \\
\hline 401 & Naphth-2-yl & 15 & 91 \\
\hline $40 m$ & Fur-2-yl & 18 & 80 \\
\hline $40 n$ & Benzofur-2-yl & 15 & 87 \\
\hline 400 & Pyridin-2-yl & 15 & 95 \\
\hline 40p & Quinolin-2-yl & 18 & 97 \\
\hline
\end{tabular}

Scheme 8: Synthesis of imidazolines via ultrasound

\section{Nanoparticles from azolines}

Recently, nanoparticles have come to light as entities with medical

applications, including their possible use as carriers in drug delivery to the target site or gene delivery to tumors, as well as contrast agents in imaging [25]. In this context, 2-methyl-2-oxazoline was taken as the raw material for a nanostructural material (PMeOX-silica hybrid nanoparticles) [26] that can be used in biomedical applications.

PMeOX-silica hybrid nanoparticles were prepared by using the "grafting to" method and either click chemistry or silane coupling. The first step of the method is the synthesis of the 2-methyl-2-oxazoline polymer functionalized with azide. Afterwards, a microemulsion water oil containing $\mathrm{SiO}_{2}$ is prepared separately, followed by the addition of the polymer of oxazoline. Finally, PMeOX-silica hybrid nanoparticles emerge.

\section{Imidazoles}

Imidazole (1,3-diaza-2,4-cyclopentadiene) is a five-membered organic compound having the formula $\mathrm{C}_{3} \mathrm{H}_{4} \mathrm{~N}_{2}$. As can be appreciated, it has three carbons and two nitrogens, the latter two atoms at positions 1 and 3. Its derivatives include an extensive variety of natural products such as histamine, histidine, biotin, alkaloids and nucleic acids [27].

In addition, this structure is present in a variety of pharmacologically active compounds. One example is 5-ethynyl-1beta- $D$-ribofuranosylimidazole-4-carboxamide (EICAR) 41. The most potent congener of this group has shown antiviral potency about 10 to 100 -fold greater than that of ribavirin 42 [28]. Other examples are etomidate (amidate) $\mathbf{4 3}$ and cimetidine (tagamet) 44 [4] (Figure 2).

Various imidazole derivatives had been discovered as early as the 1840s. However, it was not until 1858 that Heinrich Debus carried out the first imidazole synthesis, which was done by using glyoxal and formaldehyde in ammonia to yield imidazole [29]. Although imidazoles are of great pharmacological importance, there is no recent compendium of their current applications in the synthesis of new pharmacologically active compounds.

\section{Pharmacological activity}

The imidazole moiety is contained in the backbone of many drugs that have anticancer, antifungal, antibacterial, antitubercular, antiinflammatory, antineuropathic, antihypertensive, antihistaminic, antiparasitic, antiobesity and antiviral activity.

\section{Imidazoles in the synthesis of new biologically active compounds}

Sharma et al. reported the utility of an imidazole moiety as the precursor of 2-(substituted phenyl)- $1 \mathrm{H}$-imidazoles 47 , which has antibacterial activity. During the process of synthesis, the last step involves a direct acylation of a 2-phenylimidazole $\mathbf{4 5}$ with acyl chloride substituted 46 prepared in situ [30] (Scheme 9).

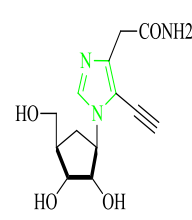

41

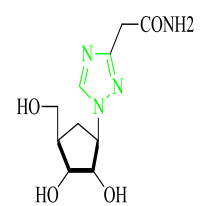

42

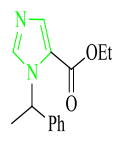

43

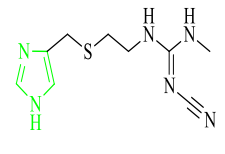

44
Figure 2: Examples of biologically active imidazoles. 


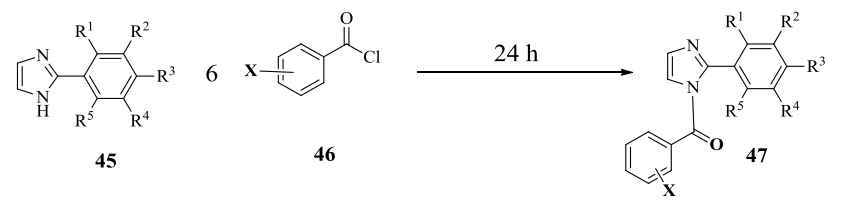

Scheme 9: Synthesis of 2-(substituted phenyl)-1H-imidazoles 7, with antibacterial activity.

Duran et al. synthesized a new series of 2-(4,5-dimethyl-1(phenylamino)- $1 \mathrm{H}$ - imidazol-2-ylthio)- $\mathrm{N}$-(thiazol-2-yl) acetamide derivatives. The reaction implied a nucleophilic displacement of the chlorine of the chloroacetamide intermediate 49 , promoted by an imidazolene-2-thione derivative 48. This process used potassium carbonate as catalyst at room temperature. These compounds were among those accepted by the National Cancer Institute for anticancer activity tests. The most effective compound of the series showed selective activity against melanoma cell lines (SK-MEL-5) [31,32] (Scheme 10).

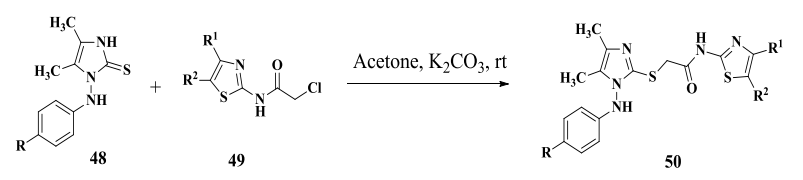

Scheme 10: Synthesis route of 2-(substituted phenyl)- $1 \mathrm{H}$-imidazoles $\mathbf{5 0}$, with anticancer activity.

Blunden et al. developed an amphiphilic block copolymer capable of self-assembling into polymeric micelles, which was successfully tested as a drug carrier for NAMI-A. This antimetastatic agent, now in Phase II clinical trials, has low cytotoxicity and is inactive against primary tumors. A polymeric form of NAMI-A was synthesized by combining an excess of polyvinyimidazole $\left(\mathrm{M}_{\mathrm{n}, \text { theo }}=14300 \mathrm{~g} \cdot \mathrm{mol}^{-1}\right)$ with the $\mathrm{Ru}$ complex in the appropriate alcohol. In the last step, a water-soluble block copolymer was designed in order to improve biocompatibility and cell uptake through the formation of micelles. It turns out that compared to the NAMI-A molecule, NAMI-A copolymer micelles are about 1.5-fold more active on cancer cell lines [33] (Scheme 11).

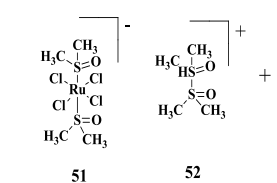

$\left[\right.$ DMSO $\left._{2} \mathrm{H}\right]$ [trans-RuIIICl 4 (DMSO) $\left.)_{2}\right]$

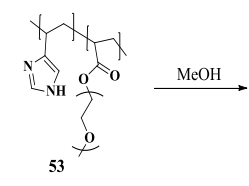

PVIm-PPEGMEA

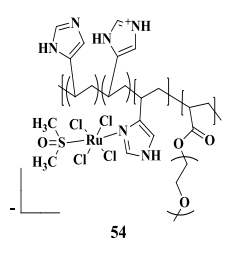

P(NAMI-A)-PPEGMEA
Scheme 11: Synthesis route of NAMI-A copolymer micelles 54, with anticancer activity.

On the other hand, Ramachandran et al. synthesized analogues of 1-[2-(1H-imidazo-1-yl)acetyl]-2,6-diarylpiperidin-4-ones 57 . In this process imidazole was introduced via nucleophilic substitution with $\mathrm{N}$-chloroacetyl-2,6-diarylpiperidin-4-ones $\mathbf{5 5}$ under reflux to achieve the desired compounds. It is noteworthy that imidazole is a critical motif for the antifungal activity of the new prodrugs [34] (Scheme 12).

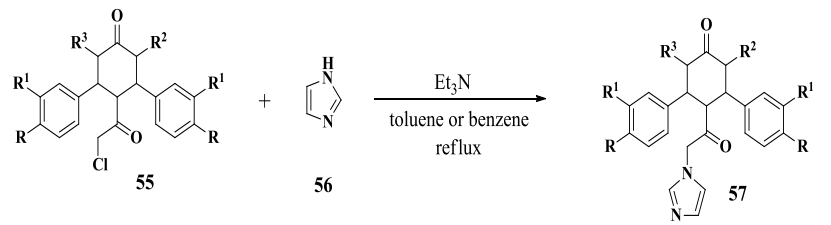

Scheme 12: Synthesis route of 1-[2-(1H-imidazo-1-yl)acetyl]-2,6-diarylpiperidin-4ones $\mathbf{5 7}$, with antifungal activity.
Kantevari et al. synthesized 2-butyl-4-chloro-1-methylimidazoles 60 with embedded aryl- and heteroaryl-derived chalcones. These compounds were tested as inhibitors of angiotensin converting enzyme (ACE). The synthesis strategy involved the Claisen- Schmidt condensation of several aryl or heteroaryl methyl ketones of type $\mathbf{5 9}$ with imidazole-5-carbaldehyde 58. This procedure was catalyzed by means of $10 \%$ aqueous $\mathrm{NaOH}$ in methanol for 3.0-5.0 $\mathrm{h}$ at room temperature. When screening all the new compounds with the colorimetric ACE inhibition assay, the most active inhibitors, of type 60, were found to have an $\mathrm{IC}_{50}$ of 2.24-3.60 $\mu \mathrm{M}$. These values show that some derived chalcones are $\sim 100$ times more active than various chalcones and flavonoids of synthetic and natural origin [35] (Scheme 13).

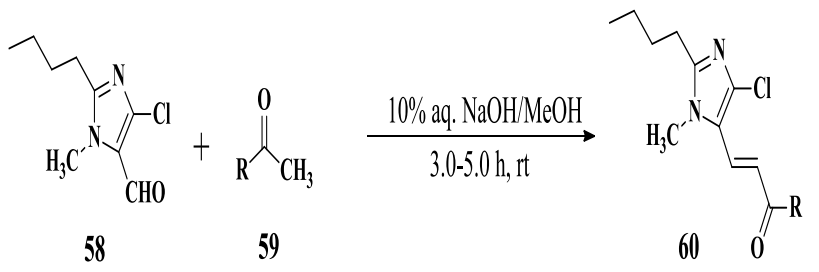

Scheme 13: Synthesis route of 2-butyl-4-chloro-1-methylimidazole chalcones 60 with antihypertensive activity.

Recently, Patil et al. carried out the synthesis of 2,3-disubstitutedimidazolyl-quinazolin-4(3H)-one derivatives 63a, b with good yields. The synthesized compounds exhibited anti-inflammatory and antimicrobial activity. Through in vitro experiments, some 2,3-disubstituted-imidazolyl-quinazolin-4(3H)-one compounds were found to be as active as prednisolone. Interestingly, the presence of electron-withdrawing groups on the quinazolinone nucleus was related to biological activity. An in vivo anti-inflammatory assay showed that compounds having an electron-withdrawing group had an important pharmacological response. The synthesis is based on the reaction between 6,8-substituted- 2-methyl-4H-3,1-benzoxazin-4-ones 61a or 6,8-substituted-2-phenyl-4H-3,1-benzoxazin-4- ones $\mathbf{6 1 b}$ and aminoimidazole $\mathbf{6 2}$, in refluxing glacial acetic acid and sodium acetate or in refluxing dry pyridine [36] (Scheme 14).
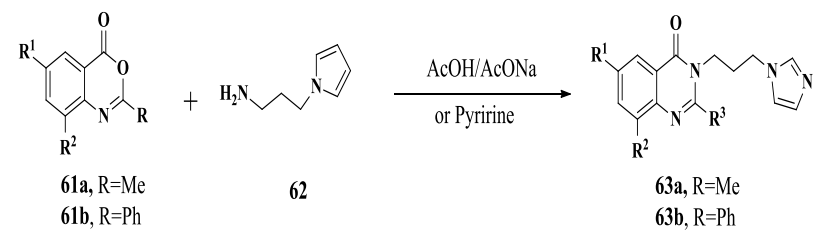

Scheme 14: Synthesis of 2,3-disubstitutedimidazolylquinazolin-4(3H)-one derivatives 63a-b, with anti-inflammatory activity.

In 2009, Zang et al. carried out the synthesis of 2-(1-(naphthalen1-yl)-1H-imidazol-2-ylthio)acetamides $\quad \mathbf{6 6 a}$ and 2 -(1-(aril)- $1 H$ -

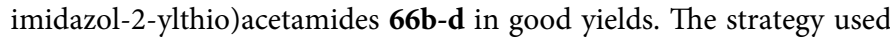
$\mathrm{N}-1$ substituted 2-mercapto-imidazoles $\mathbf{6 4 a - d}$ intermediates, which react with suitable 2-chloro- $N$-aryl-substituted acetamides $\mathbf{6 5}$ in the presence of a basic catalyst. Two of the title compounds exhibited antiHIV activity, showing an $\mathrm{IC}_{50}$ of $0.18 \mu \mathrm{M}$ and $0.20 \mu \mathrm{M}$, in MT- 4 cells infected with wild-type HIV-1 strain IIIB and HIV-2 strain ROD. These derivatives were more effective than the reference drugs, nevirapine (NVP) and delaviridine (DLV). Docking studies and preliminary SAR results provided the foundation for the rational modification of novel azole thioacetanilides in order to improve the current anti-HIV drugs [37] (Scheme 15). 


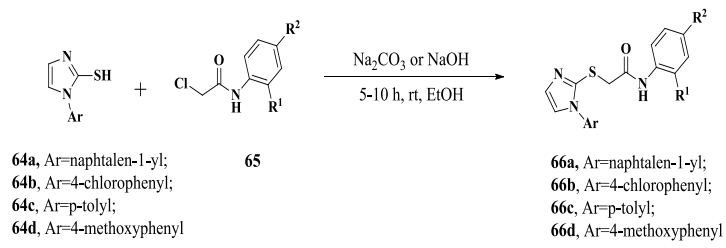

Scheme 15: Synthesis of imidazole thioacetanilides $66 \mathrm{a}-\mathrm{d}$, with anti-HIV activity.

Recently, Charton et al. synthesized imidazole-derived 2-[N-carbamoylmethyl-alkylamino]acetic acids, which have antidiabetic activity and are useful in the treatment of Alzheimer's disease. The 70, 72 and $\mathbf{7 3}$ type compounds inhibit insulin degrading enzyme (IDE), which has been involved in the physiopathology of diabetes and Alzheimer's disease. The synthesis is based on the formation of two key intermediates. The first path starts with the ring opening reaction of anhydride 67 , promoted by the amino group of 68 to yield 70. On the other hand, path 2 involved a reaction between the same intermediate 67 and a L-(Trt)histidine methyl ester hydrochloride 69. The consecutive deprotection of $\mathbf{7 1}$ with TFA delivers the title compound 72, and additional amydolysis of 72 gives 73 [38] (Scheme 16).

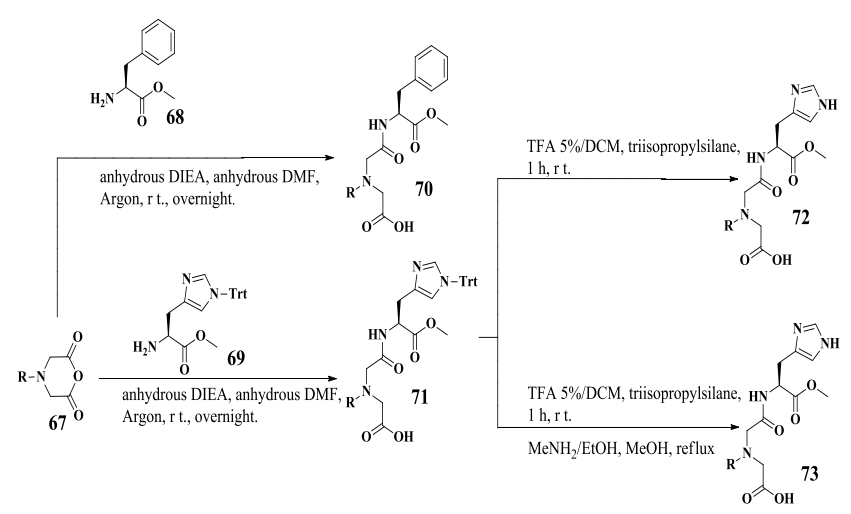

Scheme 16: Synthesis route of imidazole-derived 2-[N-carbamoylmethylalkylamino]acetic acids, which have antidiabetic activity and are useful for treating Alzheimer's disease.

\section{Perspectives}

We hope that the data reviewed presently will stimulate new and more efficient synthesis strategies and the design of more effective drugs based on this type of heterocycles with azolines and imidazoles. On the other hand, it can be foreseen that the application of MW and ultrasonication energy in the synthesis of these heterocyclic rings will increase because of the advantages that exist.

\section{Conclusions}

Based on their wide range of therapeutic activities, azolines e imidazoles are attractive molecules for the challenges that exist in medicinal chemistry. We herein show that azoline and imidazole rings are present as a core structural component in an array of medicinal applications, including antibacterial, antimicrobial, anti-inflammatory, analgesic, antiviral, antihypertensive, antifungal, anticancer, antioxidant and antidiabetic activity. These heterocycles have also been useful as quorum sensing inhibitors, cytotoxic agents against human leukemia, treatment of Alzheimer's disease, and inhibitors of $\mathrm{BChE}, \mathrm{ChE}$ and $\mathrm{CaE}$. Whereas some of the methods for obtaining these heterocycles are based on conventional strategies, others employ microwave and ultrasound energies. Finally, we have mentioned the use of oxazolines for the preparation of nanostructural material with biomedical applications.

\section{Acknowledgments}

AR is grateful for financial support from the IPN (SIP Grant 20161622) and Conacyt (Grant 240808). JTJ thanks Conacyt and IPN for scholarships.

\section{References}

1. Szabo B (2002) Imidazoline antihypertensive drugs: a critical review on their mechanism of action. Pharmacology \& therapeutics 93: 1-35.

2. Analysts Rx Product Desk Reference (2001) Merrill Lynch, London, UK.

3. Brunton $L$ (2006) The Pharmacological Basis of Therapeutics. In: Adrenergic Agonists and Antagonists. 11th edn. Goodman and Gillman.

4. Ahmadia A, Ebrahimzadehb MA, Ahmad-Ashrafia S, Karamib M, Mahdavic MR, et al. (2011) Hepatoprotective, antinociceptive and antioxidant activities of cimetidine, ranitidine and famotidine as histamine $\mathrm{H} 2$ receptor antagonists. Fund Clin Pharmacol 25: 72-79.

5. Crouch RD (2009) Synthetic routes toward 2-substituted 2-imidazolines Tetrahedron 65: 2387-2397.

6. Krasavin M (2015) Biologically active compounds based on the privileged 2-imidazoline scaffold: the world beyond adrenergic/imidazoline receptor modulator. Eur J Med Chem 97: 525-537.

7. Nikolic K, Agbaba D (2012) Pharmacophore development and SAR studies of imidazoline receptor ligands. Mini Rev Med Chem 12: 1542-1555.

8. Gulevich AV, Zhdanko AG, Orru RV, Nenajdenko VG (2010) Isocyanoacetate derivatives: synthesis, reactivity, and application. Chem Rev 110: 5235-5331.

9. Gaumont AC, Gulea M, Levillain J (2009) Overview of the chemistry of 2-thiazolines. Chem Rev 109: 1371-1401.

10. De Luca L (2006) Naturally occurring and synthetic imidazoles: their chemistry and their biological activities. Curr Med Chem 13: 1-23.

11. Sarnpitak P, Mujumdar P, Morisseau C, Hwang SH, Hammock B, et al. (2014) Potent, orally available, selective COX-2 inhibitors based on 2-imidazoline core. Eur J Med Chem 84: 160-172.

12. Reyes-Arellano A, Bucio-Cano A, Montenegro-Sustaita M, Curiel-Quesada E Salgado-Zamora H (2012) Imidazolines as non-classical bioisosteres of $\mathrm{N}$-acyl homoserine lactones and quorum sensing inhibitors. Int J Mol Sci 13: 1284 1299.

13. Bucio-Cano A, Reyes-Arellano A, Correa-Basurto J, Bello M, Torres-Jaramillo $\mathrm{J}$, et al. (2015) Targeting quorum sensing by designing azoline derivatives to inhibit the N-hexanoyl homoserine lactone-receptor CviR: Synthesis as well as biological and theoretical evaluations. Bioorg Med Chem 23: 7565-7577.

14. Nicolaou KC, Lizos DE, Kim DW, Schlawe D, de Noronha RG, et al. (2006) Total synthesis and biological evaluation of halipeptins $A$ and $D$ and analogues. J Am Chem Soc 128: 4460-4470.

15. Murai K, Morishita M, Nakatani R, Kubo O, Fujioka H, et al. (2007) Concise total synthesis of (-)-spongotine A. J Org Chem 72: 8947-8949.

16. Gribble GW (2003) Natural Production of Organohalogen Compounds: The Handbook of Environmental Chemistry Anthropogenic Compounds. Springer Science \& Business Media. ISBN 3540418423, 9783540418429.

17. Ying Y, Hong J (2007) Synthesis of brasilibactin A and confirmation of absolute configuration of $\beta$-hydroxy acid fragment. Tetrahedron Lett 48: 8104-8107.

18. Hassani R, Kacem Y, Ben Mansour H, Ben Ammar H, Ben Hassine B (2014) New chiral 4-substituted 2-cyanoethyl-oxazolines: synthesis and assessment of some biological activities. Chem Biol Interact 217: 41-48.

19. Padmavathi V, Mahesh K, Dinneswara RG, Padmaja A (2010) Synthesis and bioassay of pyrrolyl oxazolines and thiazolines. Eur J Med Chem 45: 3178-3183.

20. Altintop M, Asim Z, Akalin G, Demirel R (2014) Synthesis and biological evaluation of thiazoline derivatives as new antimicrobial and anticancer agents. Eur J Med Chem 74: 264-277.

21. Makhaeva GF, Boltneva NP, Lushchekina SV, Serebryakova OG, Stupina TS, et al. (2016) Synthesis, molecular docking and biological evaluation of N,Ndisubstituted 2-aminothiazolines as a new class of butyrylcholinesterase and carboxylesterase inhibitors. Bioorg Med Chem 24: 1050-1062. 
Citation: Reyes-Arellano A, Gómez-García O, Torres-Jaramillo J (2016) Synthesis of Azolines and Imidazoles and their Use in Drug Design. Med Chem (Los Angeles) 6: 561-570. doi:10.4172/2161-0444.1000400

22. Khanum SA, Khanum NF, Shashikanth M (2008) Synthesis and antiinflammatory activity of 2-aryloxy methyl oxazolines. Bioorg Med Chem Lett 18: $4597-4601$

23. Mason T, Peters D (2003) Practical Sonochemistry: Power Ultrasound Uses and Applications. 2nd edn. Hoorwood Publishing. ISBN: 978-1-898563-83-9.

24. Sant'Anna Gda S, Machado P, Sauzem P, Rosa F, Rubin M (2009) Ultrasound promoted synthesis of 2-imidazolines in water: A greener approach toward monoamine oxidase inhibitors. Bioorg Med Chem Lett 19: 546-549.

25. Murthy SK (2007) Nanoparticles in modern medicine: state of the art and future challenges. Int J Nanomedicine 2: 129-141.

26. Bissadi G, Weberskirch R (2016) Efficient synthesis of polyoxazoline-silica hybrid nanoparticles by using the "grafting-onto" approach. Polym Chem 7: 1271-1280.

27. Kleeman A, Engel J, Kutscher B, Reichert D (1999) Pharmaceutical Substances: Syntheses, Patents, Applications of the Most Relevant APIs. 3rd edn. Thieme Medical, New York, NY, USA

28. De Clercq E, Cools M, Balzarini J, Snoeck R, Andrei G, et al. (1991) Antivira activities of 5-ethynyl-1-beta-D-ribofuranosylimidazole-4- carboxamide and related compounds. Antimicrob Agents Chemother 35: 679-684.

29. Debus H (1858) Ueber die Einwirkung des Ammoniaks auf Glyoxal. Annalen der Chemie und Pharmacie 107: 199-208.

30. Sharma D, Narasimhan B, Kumar P, Judge V, Narang R, et al. (2009) Synthesis, antimicrobial and antiviral evaluation of substituted imidazole derivatives. Eur $\mathrm{J}$ Med Chem 44: 2347-2353.
31. Duran M, Canbaz MC (2013) pKa Determination of Newly Synthesized $\mathrm{N}$-(benzothiazole-2-yl)-2-(4,5-dimethyl-1-(phenylamino)-1H-imidazol-2-ylthio) acetamide Derivatives. Ind Eng Chem Res 52: 8355-8360.

32. Duran M, Demirayak S (2013) Synthesis of 2-[4,5-dimethyl-1-(phenylamino)$1 \mathrm{H}$-imidazol-2-ylthio]- $\mathrm{N}$-(thiazole-2-yl)acetamide derivatives and their anticancer activities. Med Chem Res 22: 4110-4124.

33. Blunden M, Rawal A, Lu H, Stenzel MH (2014) Superior Chemotherapeutic Benefits from the Ruthenium-Based Anti-Metastatic Drug NAMI-A through Conjugation to Polymeric Micelles. Macromolecules 47: 1646-1655.

34. Ramachandran R, Rani M, Senthan S, Jeong YT, Kabilan S (2011) Synthesis spectral, crystal structure and in vitro antimicrobial evaluation of imidazole/ benzotriazole substituted piperidin-4-one derivatives. Eur J Med Chem 46: 1926-1934.

35. Kantevari S, Addla D, Bagu PK, Sridhar B, Banerjee SK (2011) Synthesis and evaluation of novel 2-butyl-4-chloro-1-methylimidazole embedded chalcones and pyrazoles as angiotensin converting enzyme (ACE) inhibitors. Bioorg Med Chem 19: 4772-4781.

36. Patil DA, Surana SJ (2016) Synthesis, biological evaluation of 2,3-disubstitutedimidazolyl/benzimidazolyl-quinazolin-4(3H)-one derivatives. Med Chem Res 25: 1125-1139.

37. Zhan P, Liu X, Zhu J, Fang Z, Li Z, et al. (2009) Synthesis and biological evaluation of imidazole thioacetanilides as novel non-nucleoside HIV-1 reverse transcriptase inhibitors. Bioorg Med Chem 17: 5775-5781.

38. Charton J, Gauriot M, Guo Q, Hennuyer N, Marechal X, et al. (2014) Imidazolederived 2-[N-carbamoylmethyl-alkylamino]acetic acids, substrate-dependent modulators of insulin-degrading enzyme in amyloid- $\beta$ hydrolysis. Eur $\mathrm{J}$ Med Chem 79: 184-193 